\title{
BEM Utility for Simulation of Linear Thermal Bridges
}

\author{
Anna Justyna Werner-Juszczuk, Piotr Rynkowski \\ Biatystok University of Technology \\ Faculty of Civil and Environmental Engineering, HVAC Department \\ E-mail: p.rynkowski@pb.edu.pl,a.juszczuk@pb.edu.pl
}

Received: 09 December 2015; revised: 03 January 2016; accepted: 29 January 2016; published online: 23 March 2016

\begin{abstract}
This paper aims to prove utility of the boundary element method for modelling 2D heat transfer in complex multiregions, particularly in thermal bridges. It proposes BEM as an alternative method commonly applied in commercial software for simulation of temperature field and heat flux in thermal bridges, mesh methods (FEM, FDM).The BEM algorithm with Robin boundary condition is developed for modelling 2D heat transfer in complex multi-regions. Simulation is performed with the authoring Fortran program. The developed mathematical algorithm and computer program are validated according to standard EN ISO 10211:2007. Two examples of complex thermal bridges that commonly appears in house building are presented. Analysis of two reference cases, listed in standard ISO, confirms utility of the proposed BEM algorithm and Fortran program for simulation of linear thermal bridges. Conditions, quoted in standard ISO, are satisfied with models of a relatively small number of boundary elements. Performed validation constitutes the base for further development of BEM as an efficient method for modelling heat transfer in building components, and for the prospective application in commercial software.
\end{abstract}

Key words: linear thermal bridges, multi-region, boundary element method, heat transfer

\section{INTRODUCTION}

Analysis of heat conduction in multi-regions is significant for scientific and engineering problems. Simulation of temperature field and heat flux is essential in the process of designing and technical optimisation of many engineering objects, such as building components.

Commonly applied methods for the heat transfer problem are mesh methods, such as the finite element method (FEM), finite difference method (FDM) or finite volume method (FVM) [1]. Some BEM algorithms have already been developed for analysis of heat conduction in $2 \mathrm{D}[2,3]$ and 3D multi-regions [4-6]. Based on available literature, the BEM analysis of heat conduction problem in multi-regions mostly concern the regions consist of small number of subregions, and for those simple regions the efficiency of the method is proved. Gao and Wang [7] verified the proposed method called the interface integral boundary element method (IIBEM), solving 2D heat conduction over a two-layered rect- angular plate, over a two-layered thick-wall cylinder and solving 3D heat conduction over a two-section joint cylinder. Gao and Davies [8] validated the BEM algorithm which deals with edge and corners that appear in the intersections and boundaries with two simple examples: a three-zoned cube and a four-zoned thick cylinder. Atalay et al. [9] proved the efficiency of BEM for solving the heat conduction problem in a simple 2D multi-regions square and circular domains. Majchrzak [10] developed and verified BEM algorithms for a generation of temperature fields in 2D multi-regions, consisting of two sub-regions. Xu and Yang [11] verified the virtual boundary meshless least squares collocation method, derived from the virtual boundary element method (VBEM), for 2D four-zoned objects. Branco et al. [12] applied BEM for modelling heat conduction in double brick walls with an insulation layer. Another example of BEM application in multi-regions is the analysis of transient heat transfer. In [13] the modelling of the 3D transient heat conduction problem of cylindrical inclusions is presented. The solution of transient 
heat conduction in a three-zone object is presented in [14]. The inverse problem of $1 \mathrm{D}$ transient heat conduction in a two-zoned domain is analysed in [15].

The object of this paper is the analysis of heat transfer in building components, that is in complex multi-regions with thermal bridges.

There are many methods for simulation of temperature field and heat flux in building components, such as analytical methods [16, 17], the frequency response method [18] and methods based on IR thermographic measurements [19].

So far, some attempts to use BEM for modeling thermal bridges have been made by Tadeu et al. In [20], the mathematical algorithm has been developed for analysis of linear thermal bridges. A computational algorithm was formulated in the frequency domain for transient and steady heat conduction, where external and internal temperatures are time-dependent. the developed method was applied simple multi-region, that is for the corner of a two-layer wall for different thermal insulation configurations.

Nevertheless, the most popular methods for determination of temperature and heat flux in thermal bridges are mesh methods. To the authors' best knowledge, all available commercial programs for modelling bulling components applied either the finite difference (HEAT 2, HEAT 3, KOBRA, BISCO, TRISCO) or the finite element method (THERM, SAT). Hence, the need of developing and validation of the BEM program for solving heat conduction problems in complex thermal bridges is confirmed.

The aim of this work is to prove the utility of BEM for modelling heat transfer in building components with thermal bridges and to propose the alternative tool to mesh methods for a numerical simulation of this problems. For this kind of problems this is an innovative idea, because BEM is not widely applied for analysis of thermal bridges. The subject of this paper is the presentation of the implemented BEM algorithm and validation of authoring BEM program in accordance with standard ISO 10211 [21], relating to numerical simulations of heat transfer in thermal bridges. In the paper two examples of modeling heat conduction in real building components, that is wall-roof junction and wall-balcony board junction, are presented. The analysis of two cases, described in ISO 10211 [21], both with two examples, proves the utility of BEM for modeling heat transfer in building components.

\section{MATHEMATICAL DESCRIPTION}

Analysis of 2D steady heat transfer in multi-regions can be essentially reduced to the heat conduction problem described by the Laplace equation:

$$
\nabla^{2} T(\boldsymbol{p})=0
$$

with boundary conditions

$$
T(\boldsymbol{p})=T_{L}(\boldsymbol{p}) ; \quad \boldsymbol{p} \in L_{T},
$$

$$
\begin{gathered}
-\lambda \frac{\partial T(\boldsymbol{p})}{\partial n_{\boldsymbol{p}}}=q_{L}(\boldsymbol{p}) ; \quad \boldsymbol{p} \in L_{q}, \\
-\lambda \frac{\partial T(\boldsymbol{p})}{\partial n_{\boldsymbol{p}}}=q_{L}(\boldsymbol{p})=\alpha\left(T(\boldsymbol{p})-T_{a}\right) ; \quad \boldsymbol{p} \in L_{\alpha},
\end{gathered}
$$

in flat domain $\Lambda$ bounded with $L=L_{T} \cup L_{q} \cup L_{\alpha}$. The Dirichlet condition (1a) assumes the value of temperature $T_{L}$ at any point $\boldsymbol{p}$ on boundary line $L_{T}$. The Neumann (1b) condition assumes the value of heat flux $q_{L}$ at any point $\boldsymbol{p}$ on boundary line $L_{q}$. The Robin condition (1c) assumes the known value of heat flux at any point $\boldsymbol{p}$ on boundary line $L_{\alpha}$, that depends on value of temperature $T$, value of ambient temperature $T_{a}$ and heat exchange coefficient $\alpha$. Heat flux $q_{L}(\boldsymbol{p})$ is defined as product of thermal conductivity $\lambda$ and normal derivative of temperature $T$ at point $\boldsymbol{p}$.

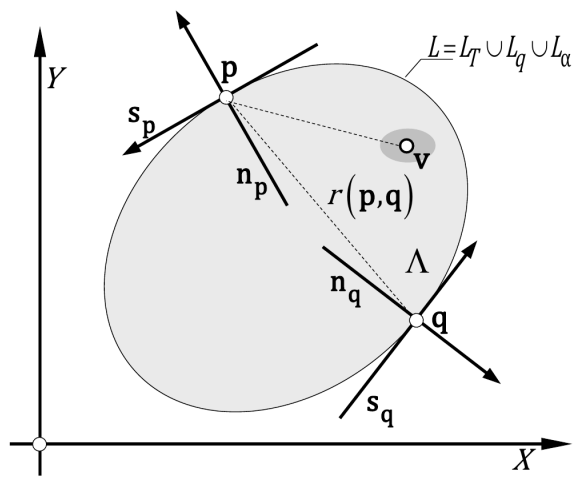

Fig. 1. Domain with boundary conditions

The sketch for a two dimensional boundary problem analysis of Laplace equation (1) is depicted in Fig. 1. It presents the $\Lambda$ domain located in the Cartesians coordinates $X Y$ and limited with the boundary $L$. The $\boldsymbol{p}$ is named the source or reference point, whilst point $\boldsymbol{q}$ is the observer or integration point, $r(\boldsymbol{p}, \boldsymbol{q})$ denotes the distance between these points; $\boldsymbol{n}_{\boldsymbol{p}}$ and $\boldsymbol{n}_{\boldsymbol{q}}$ denote the normal vectors to boundary line $L$ at points $\boldsymbol{p}$ and $q$ respectively, whilst the $s_{p}$ and $s_{q}$ the tangent vectors to boundary line $L$ at points $\boldsymbol{p}$ and $\boldsymbol{q}$. The point $\boldsymbol{v}$ is the point located inside $\Lambda$ domain.

Temperature in domain $\Lambda$, which constitutes the solution of differential equation (1) with boundary conditions (1a), (1b) and (1c) is described with the integral equation (2) [3]:

$$
\begin{aligned}
& T(\boldsymbol{p})+\int_{L_{T}} q(\boldsymbol{q}) G(\boldsymbol{p}, \boldsymbol{q}) d L_{T}+\int_{L_{\boldsymbol{q}}} q_{L}(\boldsymbol{q}) G(\boldsymbol{p}, \boldsymbol{q}) d L_{\boldsymbol{q}} \\
+ & \int_{L_{\alpha}}\left[\alpha\left(T(\boldsymbol{q})-T_{a}\right)\right] G(\boldsymbol{p}, \boldsymbol{q}) d L_{\alpha}{ }^{6}= \\
= & \int_{L_{T}} T_{L}(\boldsymbol{q}) H(\boldsymbol{p}, \boldsymbol{q}) d L_{T}+\int_{L_{q}} T(\boldsymbol{q}) H(\boldsymbol{p}, \boldsymbol{q}) d L_{\boldsymbol{q}} \\
+ & \int_{L_{\alpha}} T(q) H(p, \boldsymbol{q}) d L_{\alpha} ; \quad \boldsymbol{p}, \boldsymbol{q} \in L L=L_{T} \cup L_{q} \cup L_{\alpha}
\end{aligned}
$$


Fundamental solutions $G(\boldsymbol{p}, \boldsymbol{q})$ and $H(\boldsymbol{p}, \boldsymbol{q})$ for $\boldsymbol{p} \neq \boldsymbol{q}$ are respectively equal [3], [10]:

$$
\begin{aligned}
& G(\boldsymbol{p}, \boldsymbol{q})=-\frac{1}{2 \pi \lambda} \ln r(\boldsymbol{p}, \boldsymbol{q}) \quad ; \quad r(\boldsymbol{p}, \boldsymbol{q})=|\boldsymbol{p}-\boldsymbol{q}|(2 \mathrm{a}) \\
& H(\boldsymbol{p}, \boldsymbol{q})=\frac{\partial G(\boldsymbol{p}, \boldsymbol{q})}{\partial n_{\boldsymbol{p}}}=\frac{1}{2 \pi} \frac{\left(x_{\boldsymbol{q}}-x_{\boldsymbol{p}}\right) \boldsymbol{n}_{x}+\left(y_{\boldsymbol{q}}-y_{\boldsymbol{p}}\right) \boldsymbol{n}_{y}}{r^{2}(\boldsymbol{p}, \boldsymbol{q})}
\end{aligned}
$$

and for $\boldsymbol{p}=\boldsymbol{q}$ have the following form:

$$
\begin{gathered}
G\left(\boldsymbol{q}_{j}, \boldsymbol{q}_{j}\right)=\frac{L_{j}}{2 \pi \lambda}\left(1+\ln \frac{2}{L_{j}}\right), \\
H\left(\boldsymbol{q}_{j}, \boldsymbol{q}_{j}\right)=0,
\end{gathered}
$$

where $L_{j}-$ is the length of $j$ boundary element, $x_{\boldsymbol{q}}$ and $x_{\boldsymbol{p}}$ are the $x$ coordinates of $\boldsymbol{q}$ and $\boldsymbol{p}$ points, respectively, $y_{\boldsymbol{q}}$ and $y_{\boldsymbol{v}}$ are the $y$ coordinates of this points, $\boldsymbol{n}_{x}$ and $\boldsymbol{n}_{y}$ denote the $x$ and $y$ components of normal vector $\boldsymbol{n}$ at point $\boldsymbol{p}$.

Discrete solution of integral equation (2) can be obtained approximating the boundary line by the finite set of partial lines (constant elements are applied):

- $L_{T}$ is divided into $m$ boundary elements of known value of temperature $T_{L}$,

- $L q$ is divided into $n$ elements, where the heat flux $q_{L}$ is known,

- $L_{\alpha}$ is divided into $l$ elements, where the Robin condition is assumed $q_{L}=\alpha\left(T-T_{a}\right)$.

Hence, the equation (2) takes the form:

$$
\begin{aligned}
& {\left[\begin{array}{lll}
\boldsymbol{H}_{m} & \boldsymbol{H}_{n} & \boldsymbol{H}_{l}
\end{array}\right]\left[\begin{array}{l}
\boldsymbol{T}_{L, m} \\
\boldsymbol{T}_{n} \\
\boldsymbol{T}_{l}
\end{array}\right]=} \\
= & {\left[\begin{array}{lll}
\boldsymbol{G}_{m} & \boldsymbol{G}_{n} & \boldsymbol{G}_{l}
\end{array}\right]\left[\begin{array}{c}
\boldsymbol{q}_{m} \\
\boldsymbol{q}_{L, n} \\
\alpha\left(\boldsymbol{T}_{l}-\boldsymbol{T}_{a}\right)
\end{array}\right], }
\end{aligned}
$$

where:

- $\boldsymbol{H}_{m}, \boldsymbol{H}_{n}, \boldsymbol{H}_{l}$ - the matrices of fundamental solutions $\boldsymbol{H}(\boldsymbol{p}, \boldsymbol{q})$ consisting of $m \times m, n \times n$ and $l \times l$ elements, respectively,

- $\boldsymbol{G}_{m}, \boldsymbol{G}_{n}, \boldsymbol{G}_{l}$ - the matrices of fundamental solutions $\boldsymbol{G}(\boldsymbol{p}, \boldsymbol{q})$ consisting of $m \times m, n \times n$ and $l \times l$ elements, respectively,

- $\boldsymbol{T}_{L, m}$ - the vector of known values of temperature $T_{L}$ of size $m$,

- $\boldsymbol{T}_{n}, \boldsymbol{T}_{l}$ - the vectors of unknown values of temperature $T$ of size $n$ and $l$, respectively,

- $\boldsymbol{q}_{m}$ - the vector of unknown values of heat flux $q$ of size $m$,

- $\boldsymbol{q}_{L, n}$ - the vector of known values of heat flux $q$ of size $n$,

- $\alpha\left(\boldsymbol{T}_{l}-\boldsymbol{T}_{a}\right)-$ the vector of known $\boldsymbol{T}_{a}$ and $\alpha$ values and unknown $\boldsymbol{T}_{l}$ values of size $l$.
After rearrangement of matrices and vectors, the formula (3) may be written as:

$$
\boldsymbol{A} \boldsymbol{X}=\boldsymbol{B},
$$

where $\mathbf{X}$ is the vector of unknown values:

$$
\boldsymbol{X}=\left[\begin{array}{l}
\boldsymbol{q}_{m} \\
\boldsymbol{T}_{n} \\
\boldsymbol{T}_{l}
\end{array}\right],
$$

$\mathbf{B}$ is the vector of known values:

$$
\boldsymbol{B}=\boldsymbol{H}_{m} \boldsymbol{T}_{L, m}-\boldsymbol{G}_{n} \boldsymbol{q}_{L, n}+\alpha \boldsymbol{G}_{l} \boldsymbol{T}_{a},
$$

and $\boldsymbol{A}$ is known square coefficient matrix:

$$
\boldsymbol{A}=\left[\begin{array}{ll}
\boldsymbol{G}_{m}-\boldsymbol{H}_{n} & \alpha \boldsymbol{G}_{l}-\boldsymbol{H}_{l}
\end{array}\right] .
$$

Exemplary multi-region, for which a further algorithm is developed, consists of three sub-domains (Fig. 2).

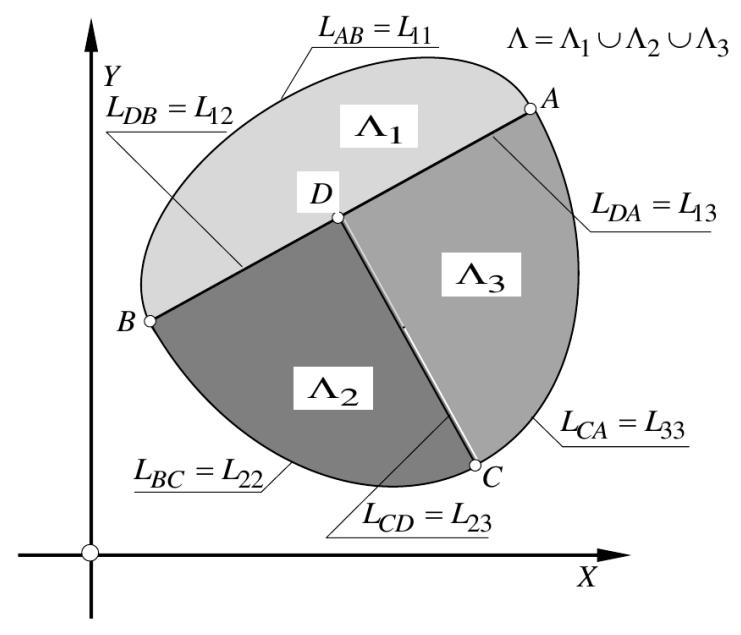

Fig. 2. Exemplary 2D multi-region $\Lambda=\Lambda_{1} \cup \Lambda_{2} \cup \Lambda_{3}$

Contact between sub-domains is perfect, thus the additional conditions of continuity of heat flux $q$ and temperature $T$, on internal lines $L_{12}, L_{13}, L_{23}$ are defined as:

$$
\begin{gathered}
{\left[\begin{array}{l}
\boldsymbol{T}_{12}^{1}=\boldsymbol{T}_{12}^{2} \\
\boldsymbol{T}_{13}^{1}=\boldsymbol{T}_{13}^{3} \\
\boldsymbol{T}_{23}^{2}=\boldsymbol{T}_{23}^{3}
\end{array}\right],} \\
{\left[\begin{array}{l}
\boldsymbol{q}_{12}^{2}=-\boldsymbol{q}_{12}^{1} \\
\boldsymbol{q}_{13}^{3}=-\boldsymbol{q}_{13}^{1} \\
\boldsymbol{q}_{23}^{3}=-\boldsymbol{q}_{23}^{2}
\end{array}\right],}
\end{gathered}
$$

where superscript (e.g. 1) relates to the number of subdomain, and subscript (e.g. 12) relates to the number of internal lines between two domains (e.g. 12 relates to the line between domain 1 and 2). 
Incorporating conditions (5a) and (5b), equation (3) can be written in the form [2]:

boundary $L_{1}=L_{11} \cup L_{12} \cup L_{13}$ of domain $\Lambda_{1}$ :

$$
\left[\begin{array}{lll}
\boldsymbol{A}_{1}^{1} & \boldsymbol{H}_{12}^{1} & \boldsymbol{H}_{13}^{1}
\end{array}\right]\left[\begin{array}{c}
\boldsymbol{X}_{1}^{1} \\
\boldsymbol{T}_{12}^{1} \\
\boldsymbol{T}_{13}^{1}
\end{array}\right]=\boldsymbol{B}_{1}^{1}+\left[\begin{array}{ll}
\boldsymbol{G}_{12}^{1} & \boldsymbol{G}_{13}^{1}
\end{array}\right]\left[\begin{array}{c}
\boldsymbol{q}_{12}^{1} \\
\boldsymbol{q}_{13}^{1}
\end{array}\right],
$$

boundary $L_{2} \equiv L_{22} \cup L_{12} \cup L_{23}$ of domain $\Lambda_{2}$ :

$$
\left[\begin{array}{lll}
\boldsymbol{A}_{2}^{2} & \boldsymbol{H}_{12}^{2} & \boldsymbol{H}_{23}^{2}
\end{array}\right]\left[\begin{array}{c}
\boldsymbol{X}_{2}^{2} \\
\boldsymbol{T}_{12}^{1} \\
\boldsymbol{T}_{23}^{2}
\end{array}\right]=\boldsymbol{B}_{2}^{2}+\left[-G_{12}^{2} \boldsymbol{G}_{23}^{2}\right]\left[\begin{array}{c}
\boldsymbol{q}_{12}^{1} \\
\boldsymbol{q}_{23}^{2}
\end{array}\right]
$$

boundary $L_{3} \equiv L_{33} \cup L_{13} \cup L_{23}$ of domain $\Lambda_{3}$ :

$$
\left[\begin{array}{lll}
\boldsymbol{A}_{3}^{3} & \boldsymbol{H}_{13}^{3} & \boldsymbol{H}_{23}^{3}
\end{array}\right]\left[\begin{array}{c}
\boldsymbol{X}_{3}^{3} \\
\boldsymbol{T}_{13}^{1} \\
\boldsymbol{T}_{23}^{2}
\end{array}\right]=\boldsymbol{B}_{3}^{3}+\left[-\boldsymbol{G}_{13}^{3}-\boldsymbol{G}_{23}^{3}\right]\left[\begin{array}{c}
\boldsymbol{q}_{13}^{1} \\
\boldsymbol{q}_{23}^{2}
\end{array}\right],
$$

where, for each subdomain, matrix $\mathrm{A}_{i}^{i}$ is derived according to formula (4c), and vectors $\mathrm{X}_{i}^{i}$ and $\mathrm{B}_{i}^{i}$ according to (4a) and (4b).

Equations (6a), (6b) and (6c) are combined in a single matrix describing the values of temperatures and heat flux on boundary lines of multi-region consists of three sub-domains.

After determination of values of temperatures $T(\boldsymbol{q})$ and heat fluxes $q(\boldsymbol{q})$ on boundary lines (external and internal) of each subdomain, the temperature $T(\boldsymbol{v})$ and heat flux $q(\boldsymbol{v})$ at each point $\boldsymbol{v}$ inside the sub-domains can be calculated from the following formula (7):

$$
T(\boldsymbol{v})=\int_{L} T(\boldsymbol{q}) H(\boldsymbol{v}, \boldsymbol{q}) \mathrm{d} L-\int_{L} q(\boldsymbol{q}) G(\boldsymbol{v}, \boldsymbol{q}) d L,
$$

where:

$$
\begin{gathered}
G(\boldsymbol{v}, \boldsymbol{q})=-\frac{1}{2 \pi \lambda} \ln r(\boldsymbol{v}, \boldsymbol{q}) \quad ; \quad r(\boldsymbol{v}, \boldsymbol{q})=|\boldsymbol{v}-\boldsymbol{q}| \\
H(\boldsymbol{v}, \boldsymbol{q})=\frac{\partial G(\boldsymbol{v}, \boldsymbol{q})}{\partial n_{\boldsymbol{v}}}=\frac{1}{2 \pi} \frac{\left(x_{\boldsymbol{q}}-x_{\boldsymbol{v}}\right) n_{x}+\left(y_{\boldsymbol{q}}-y_{\boldsymbol{v}}\right) n_{y}}{r^{2}(\boldsymbol{v}, \boldsymbol{q})} .
\end{gathered}
$$

In equations (7a) and (7b) $r(\boldsymbol{v}, \boldsymbol{q})$ denotes the distance between points $\boldsymbol{v}$ and $\boldsymbol{q} ; x_{\boldsymbol{q}}$ and $x_{\boldsymbol{v}}$ are the $x$ coordinates of these points, and $y_{\boldsymbol{q}}$ and $y_{\boldsymbol{v}}$ are the $y$ coordinates of this points, $\boldsymbol{n}_{x}$ and $\boldsymbol{n}_{y}$ denote the $x$ and $y$ components of normal vector $\boldsymbol{n}$ at point $\boldsymbol{v}$.

Basing on the proposed mathematical algorithm, the authoring program in Fortran has been written for solving the heat transfer problem in complex 2D multi-regions.

\section{PROGRAM VALIDATION}

In order to validate the developed Fortran program for the heat conduction problem in multi-regions, two examples are performed according to standard EN ISO 10211:2007 [21].
Annex A of ISO 10211 presents two test reference cases for steady-state 2D problems. In order to classify the method as a high precision method for calculation of thermal bridges, the obtained results should correspond with values presented in ISO 10211.

\section{1. Case 1}

Case 1 concerns the heat transfer through a square column with assumed values of temperatures on boundaries, for which the analytical solution at 28 points is determined (Fig. 3).

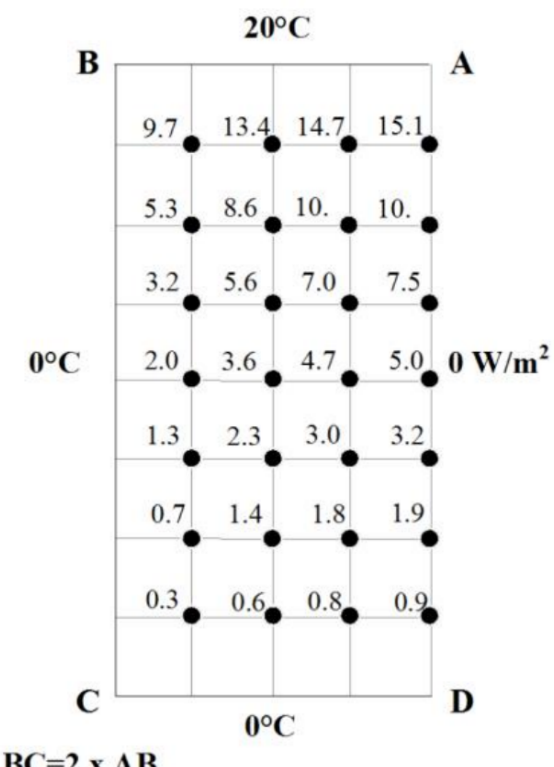

Fig. 3. Test reference case 1 - analytical solution [21]

Analysis of case 1 was performed for a various number of boundary elements. Solution error $\varepsilon$ was determined for each test from the formula:

$$
\varepsilon=\frac{\left|T_{\mathrm{ISO}}-T_{\mathrm{BEM}}\right|}{T_{\mathrm{ISO}}} \cdot 100 \%
$$

where: $T_{\text {ISO }}$ - values of temperature in accordance to ISO $10211, T_{\mathrm{BEM}}$ - values of temperature in accordance to BEM solution.

Comparison between BEM solution errors and the error of the program based on the finite difference method for points 1-28 is presented in Tab. 1 .

As it can be seen in Tab. 1, the FDM solution error for 22000 nodes is comparable to BEM solution for 300 or 400 elements. That confirms the similar BEM computational accuracy to FDM, obtained for a smaller number of algebraic equations.

According to ISO 10211, the difference between temperature listed in Fig. 3 and temperature calculated by the validated program shall not exceed $0,1^{\circ} \mathrm{C}$. Temperature (Fig. 4) 
Tab. 1. BEM solution error - case 1

\begin{tabular}{|c|c|c|c|c|c|c|c|c|c|c|c|c|c|c|}
\hline Point & 1 & 2 & 3 & 4 & 5 & 6 & 7 & 8 & 9 & 10 & 11 & 12 & 13 & 14 \\
\hline Method & \multicolumn{14}{|c|}{$\varepsilon[\%]$} \\
\hline ISO 10211 & 33.33 & 14.29 & 7.69 & 5 & 3.13 & 1.89 & 1.03 & 16.67 & 7.14 & 4.35 & 2.78 & 1.79 & 1.16 & 0.75 \\
\hline BEM 250 el. & -13.33 & -5.71 & 2.31 & -1.00 & 0.31 & 0.94 & 0.62 & -5.00 & 2.14 & $-0.8 \%$ & -1.39 & -0.18 & -0.47 & 0.15 \\
\hline BEM 300 el. & -13.33 & -5.71 & 2.31 & -1.00 & 0.31 & 0.94 & 0.52 & -5.00 & 2.86 & -0.43 & -1.39 & -0.18 & -0.47 & 0.15 \\
\hline BEM 400 el. & -13.33 & -5.71 & 3.08 & -1.00 & 0.31 & 0.94 & 0.41 & -5.00 & 2.86 & -0.43 & -1.11 & -0.18 & -0.47 & 0.15 \\
\hline $\begin{array}{l}\text { FDM } 20000 \\
\text { nodes }\end{array}$ & 13.33 & 5.71 & 3.08 & 0.50 & 0.31 & 0.94 & 0.41 & 5.00 & 2.86 & 0.43 & 1.11 & 0.18 & 0.47 & 0.15 \\
\hline Point & 15 & 16 & 17 & 18 & 19 & 20 & 21 & 22 & 23 & 24 & 25 & 26 & 27 & 28 \\
\hline Method & \multicolumn{14}{|c|}{$\varepsilon[\%]$} \\
\hline BEM 250 el. & -3.75 & 1.11 & 0.00 & 0.64 & -0.43 & -0.29 & -0.27 & 2.22 & -0.53 & -0.31 & 0.40 & 0.93 & 0.37 & 0.60 \\
\hline BEM 300 el. & -2.50 & 1.67 & 0.00 & 0.64 & -0.29 & -0.19 & -0.27 & 2.22 & 0.00 & 0.00 & 0.60 & 1.07 & 0.46 & 0.66 \\
\hline BEM 400 el. & -2.50 & 1.67 & 0.33 & 0.85 & -0.29 & -0.19 & -0.20 & 3.33 & 0.53 & 0.00 & 0.60 & 1.07 & 0.56 & 0.66 \\
\hline $\begin{array}{l}\text { FDM } 20000 \\
\text { nodes }\end{array}$ & 2.50 & 1.67 & 0.33 & 0.85 & 0.14 & 0.19 & 0.20 & 1.11 & 0.53 & 0.63 & 0.00 & 0.40 & 0.09 & 0.07 \\
\hline
\end{tabular}

that satisfies this condition was obtained for 250 boundary elements.

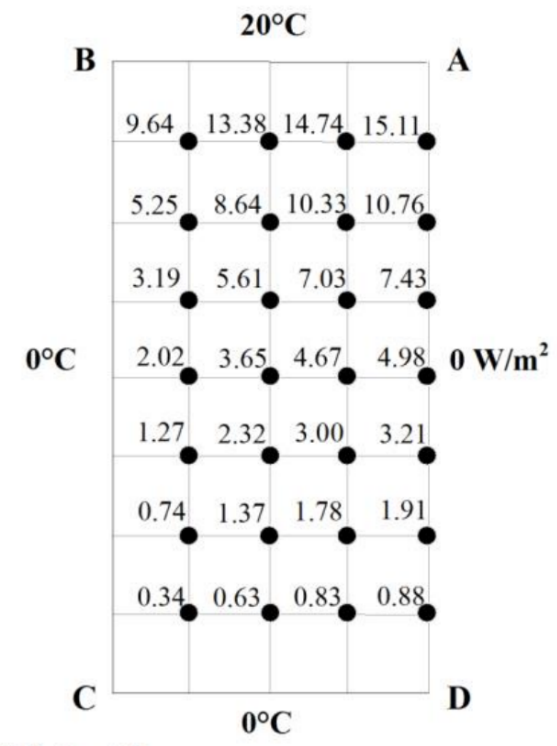

$\mathrm{BC}=2 \times \mathrm{AB}$

Fig. 4. BEM solution case $1-250$ boundary elements

Determined temperature field for 250 boundary elements is presented in Fig. 5.

Tab. 2. Test reference case 2 - temperatures and heat flux [21]

\begin{tabular}{l|l|l}
\hline \multicolumn{2}{l}{ Temperatures $\left[{ }^{\circ} \mathrm{C}\right]$} \\
\hline A: 7.1 & & B: 0.8 \\
\hline C: 7.9 & D: 6.3 & E: 0.8 \\
\hline F: 16.4 & G: 16.3 & \\
\hline H: 16.8 & & I: 18.3 \\
\hline \multicolumn{4}{l}{ Total heat flow rate: $9.5 \mathrm{~W} / \mathrm{m}$} \\
\hline
\end{tabular}

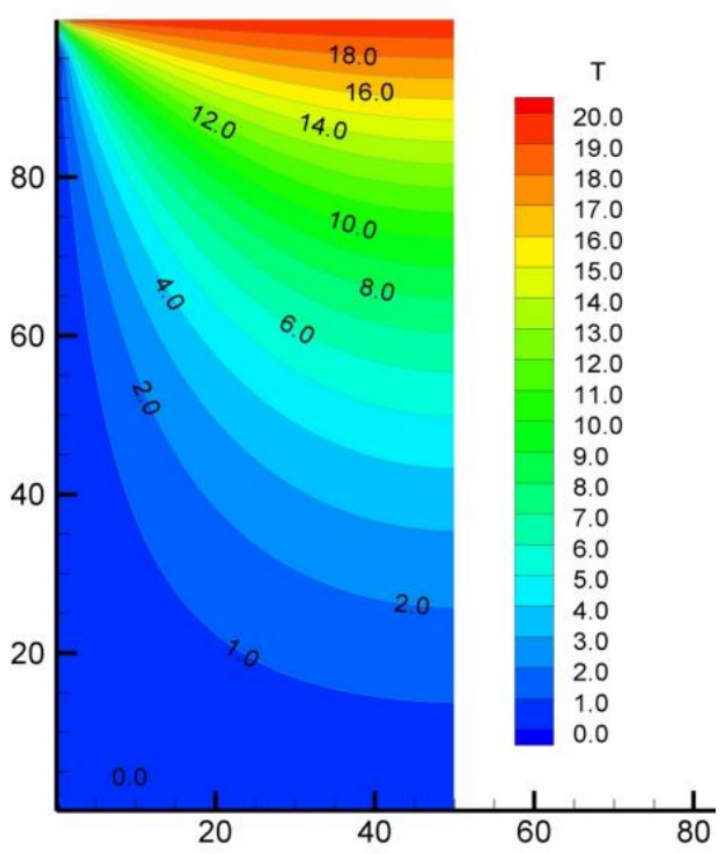

Fig. 5. Temperature field case 1 - BEM solution

\section{2. Case 2}

Case 2 concerns the more complex problem of heat transfer in a multi-region domain (Fig. 6), consisting of 4 sub-regions. Region 1 is made of concrete (thermal conductivity $\lambda=1.15 \mathrm{~W} /(\mathrm{m} \cdot \mathrm{K})), 2$ of $\operatorname{wood}(\lambda=0.12 \mathrm{~W} /(\mathrm{m} \cdot \mathrm{K}))$, and regions 3 and 4 represent the layer of insulation $(\lambda=$ $0.029 \mathrm{~W} /(\mathrm{m} \cdot \mathrm{K}))$ and aluminium $(\lambda=230 \mathrm{~W} /(\mathrm{m} \cdot \mathrm{K}))$, respectively. $\mathrm{R}_{s i}$ and $\mathrm{R}_{s e}$ denote inside and outside surface resistance, respectively $\left(\mathrm{m}^{2} \mathrm{~K} / \mathrm{W}\right)$. 
Tab. 3. BEM and FDM solution error - case 2

\begin{tabular}{l|c|c|c|c|c|c|c|c|c}
\hline Point & A & B & C & D & E & F & G & H & I \\
\hline Method & \multicolumn{7}{|c}{$\varepsilon[\%]$} \\
\hline ISO 10211 & 1.41 & 12.50 & 1.27 & 1.59 & 12.50 & 0.61 & 0.61 & 0.60 & 0.55 \\
\hline BEM 400 el. & 10.94 & 5.26 & 6.04 & 0.78 & 3.61 & 0.24 & 0.51 & 0.18 & 0.16 \\
\hline BEM 800 el. & 2.31 & 5.26 & 0.64 & 1.24 & 3.61 & 0.18 & 0.19 & 0.53 & 0.16 \\
\hline BEM 1600 el. & 1.41 & 5.26 & 0.00 & 0.00 & 3.61 & 0.30 & 0.43 & 0.30 & 0.16 \\
\hline BEM 3200 el. & 0.63 & 5.26 & 0.00 & 0.17 & 3.61 & 0.12 & 0.25 & 0.06 & 0.16 \\
\hline FDM 20 000 nodes & 0.56 & 5.00 & 0.00 & 0.48 & 3.75 & 0.00 & 0.18 & 0.18 & 0.16 \\
\hline
\end{tabular}

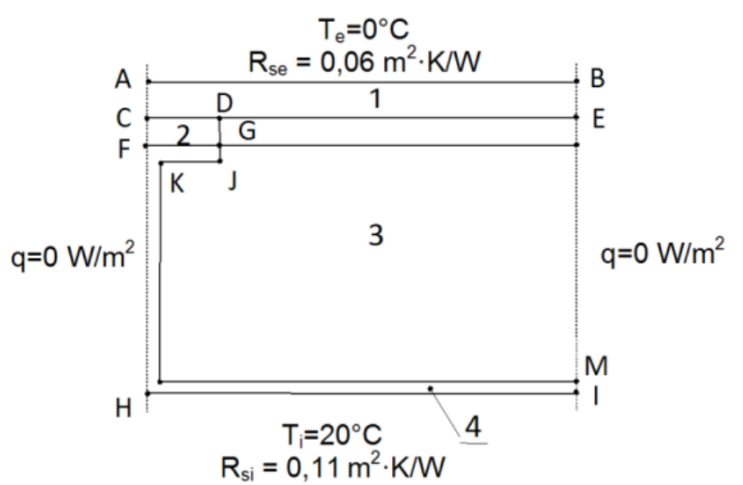

Fig. 6. Test reference case 2 - model [21]

Reference values, with which the results of simulations should be compared, are presented in Tab. 2 .

Analysis of case 2 was performed for a various number of boundary elements. Solution error was determined for each test and compared to the error of the program based on the finite difference method (Tab. 3).

Values that correspond with standard values, that is the differences between temperatures and heat flow rate do not exceed $0.1^{\circ} \mathrm{C}$ and $0.1 \mathrm{~W} / \mathrm{m}$, respectively, were obtained for 3200 boundary elements (Tab. 4). The BEM error for 3200 elements is comparable to the FDM error for 44000 elements.
Tab. 4. BEM solution case $2-3200$ boundary elements

\begin{tabular}{l|l|l}
\hline \multicolumn{3}{l}{ Temperatures $\left[{ }^{\circ} \mathrm{C}\right]$} \\
\hline A: 7.06 & & B: 0.76 \\
\hline C: 7.90 & D: 6.29 & E: 0.83 \\
\hline F: 16.42 & G: 16.34 & \\
\hline H: 16.79 & & I: 18.33 \\
\hline Average total heat flow rate: $9.48 \mathrm{~W} / \mathrm{m}$ \\
AE: $9.5 \mathrm{~W} / \mathrm{m}$ \\
HI: $-9.45 \mathrm{~W} / \mathrm{m}$
\end{tabular}

Temperature distribution in the analysed multi-region is shown in Fig. 7.

\section{CASE STUDIES}

Authoring BEM Fortran program was applied for determination of temperature field and heat flux in two thermal bridges. The analysis was performed for climatic conditions in eastern Poland, which is located in IV climatic zone, according to Polish standard PN-EN 12831:2006 [22]. The external design temperature for this geographical zone accounts for $-22^{\circ} \mathrm{C}$.

PN-EN 12831:2006 [22] specifies also the values of internal design temperature. For the purpose of the analysis, the

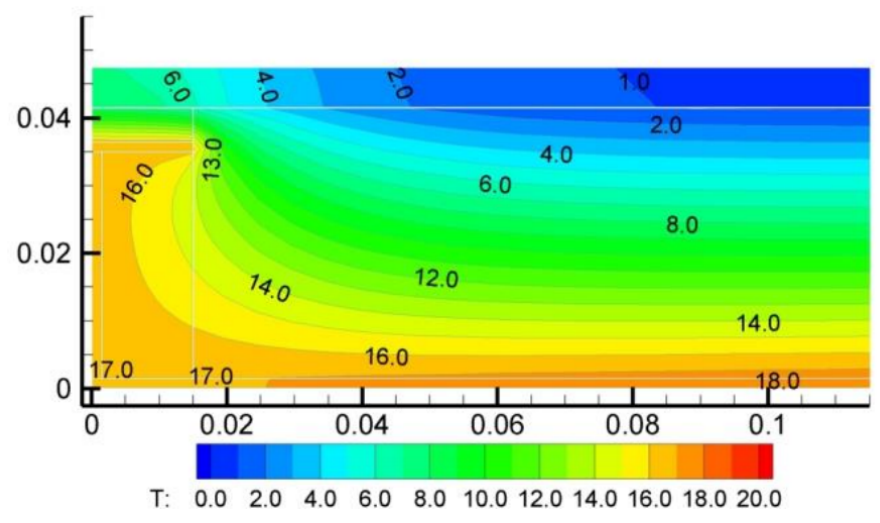

Fig. 7. Temperature field case 2-BEM solution 


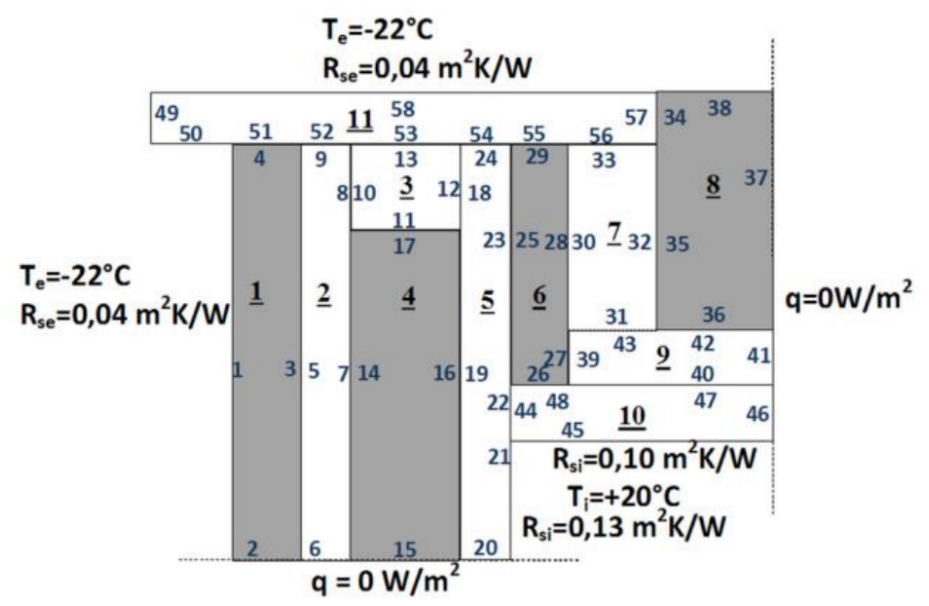

Fig. 8. Scheme of wall-roof junction with boundary conditions

temperature of $20^{\circ} \mathrm{C}$ is assumed, appropriate for residential space in house buildings.

For edges that have contact with external and internal ambient, the Robin boundary condition is assumed. Values of internal $R_{s i}$ and external $R_{s e}$ surface heat resistance are assumed in accordance with PN-EN ISO 6946 [23]. On the line of building components intersections, the Neumann condition is assumed of the heat flux of value $q=0 \mathrm{~W} / \mathrm{m}^{2}$.

Tab. 5. Material properties: wall-roof junction

\begin{tabular}{|c|c|c|c|}
\hline Region & Material & $\begin{array}{c}\text { Thermal conductivity } \\
\lambda\left[\mathrm{W} \cdot \mathrm{m}^{-1} \cdot \mathrm{K}^{-1}\right]\end{array}$ & $\begin{array}{c}\text { Dimensions } \\
{[\mathrm{cm}]}\end{array}$ \\
\hline 1 & $\begin{array}{c}\text { mineral } \\
\text { wool }\end{array}$ & 0.04 & 12 \\
\hline 2 & $\begin{array}{l}\text { wood } \\
\text { base } \\
\text { board }\end{array}$ & 0.17 & 1.2 \\
\hline 3 & rafter & 0.30 & $18 \times 9$ \\
\hline 4 & $\begin{array}{c}\text { mineral } \\
\text { wool }\end{array}$ & 0.04 & 18 \\
\hline 5 & $\begin{array}{l}\text { wood } \\
\text { base } \\
\text { board }\end{array}$ & 0.17 & 1.25 \\
\hline 6 & $\begin{array}{c}\text { mineral } \\
\text { wool }\end{array}$ & 0.04 & $24 \times 5$ \\
\hline 7 & rafter & 0.30 & $22 \times 7$ \\
\hline 8 & $\begin{array}{c}\text { mineral } \\
\text { wool }\end{array}$ & 0.04 & 23.8 \\
\hline 9 & $\begin{array}{l}\text { wood } \\
\text { base } \\
\text { board }\end{array}$ & 0.17 & 2 \\
\hline 10 & $\begin{array}{l}\text { wood } \\
\text { base } \\
\text { board }\end{array}$ & 0.17 & 1.2 \\
\hline 11 & $\begin{array}{c}\text { elevation } \\
\text { board }\end{array}$ & 0.22 & 18 \\
\hline
\end{tabular}

\section{1. Wall-roof junction}

The first example presents the wall-roof junction which is used in modular energy-saving buildings in Europe.

The analysed element is composed of wood base boards, mineral wool, wooden rafters and elevation of different dimensions and thermal properties (Tab. 5).

The considered multi-region consists of 11 sub-regions, 58 edges, where 22 edges are contact lines between particular sub-regions. The scheme of the thermal bridge with numeration of boundaries and boundary conditions is presented in Fig. 8.

Temperature field (Fig. 9) was obtained for 4400 boundary elements, that is 400 elements for each subdomain. As it can be seen, there is a continuity of isotherms between particular sub-domains, which proves the correctness of simulation done with the BEM program.

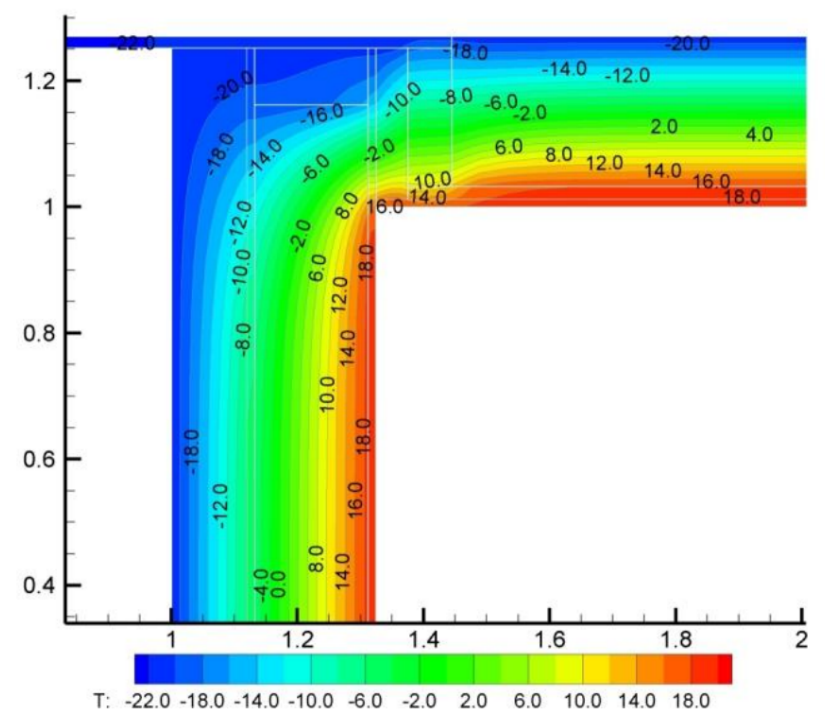

Fig. 9. Temperature distribution in wall-roof junction 


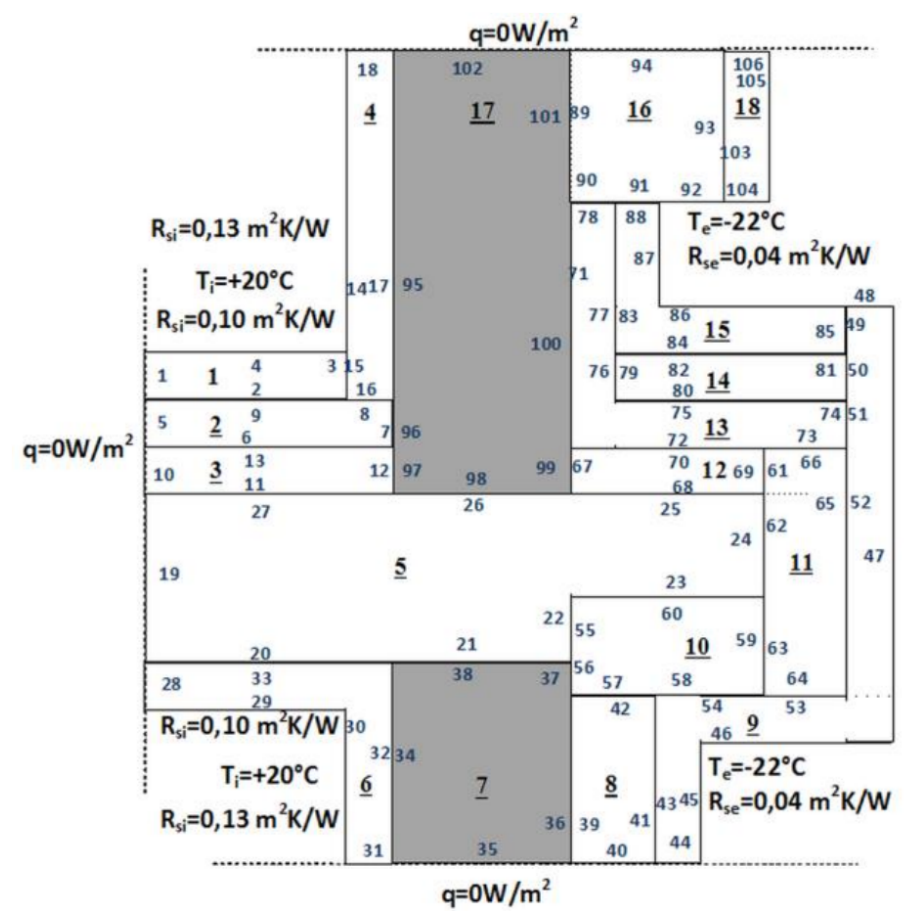

Fig. 10. Scheme of wall-balcony board junction with boundary conditions

\section{2. Wall-balcony board junction}

The second thermal bridge is the wall-balcony board junction, which often occurs in single and multi-family houses and constitutes the significant source of heat losses in buildings. In the analysed component the load-bearing wall is made of $25-\mathrm{cm}$ thick cellular concrete and insulated with 15 $\mathrm{cm}$ of styrofoam. Dimensions and thermal conductivity of all elements are listed in Tab. 6.

Tab. 6. Material properties: wall-balcony board junction

\begin{tabular}{c|l|c|c}
\hline Region & Material & $\begin{array}{c}\text { Thermal } \\
\text { conductivity } \lambda \\
{\left[\mathrm{W} \cdot \mathrm{m}^{-1} \cdot \mathrm{K}^{-1}\right]}\end{array}$ & $\begin{array}{c}\text { Dimensions } \\
{[\mathrm{cm}]}\end{array}$ \\
\hline 1 & wodden panel & 0.4 & 2 \\
\hline 2 & conrete & 1.05 & 5 \\
\hline 3 & styrofoam & 0.038 & 5 \\
\hline 4 & plaster & 0.82 & 1.5 \\
\hline 5 & ferroconcrete & 1.7 & 25 \\
\hline 6 & plaster & 0.82 & 1.5 \\
\hline 7 & cellular concrete & 0.25 & 24 \\
\hline 8 & mineral wool & 0.037 & 16 \\
\hline 9 & plaster & 0.82 & 1.5 \\
\hline $10-11$ & mineral wool & 0.041 & 10 \\
\hline 12 & cement screed & 0.52 & 5 \\
\hline 13 & polystyrene XPS & 0.036 & $11 / 8$ \\
\hline 14 & conrete & 1.05 & 5 \\
\hline 15 & ceramic tiles & 1.05 & 1.5 \\
\hline 16 & mineral wool & 0.037 & 16 \\
\hline 17 & cellular concrete & 0.25 & 24 \\
\hline 18 & plaster & 0.82 & 1.5 \\
\hline
\end{tabular}

The proposed wall-balcony board junction can be presented as a multi-region that consists of 18 sub-regions (Fig. 10). The multi-region includes 106 edges, from among 40 edges are contact lines between particular sub-regions.

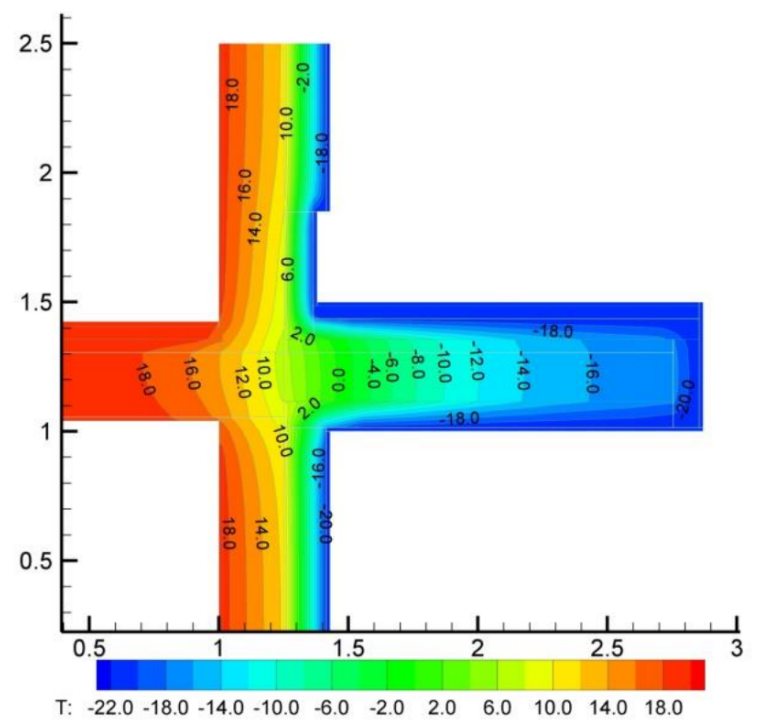

Fig. 11. Temperature distribution in wall-balcony board junction

Calculation was performed for 7200 boundary elements, that is the 400 elements on the boundary line of each subregion. Determined temperature distribution is shown in Fig. 11, and similarly to the first example, the isotherms be- 
tween particular sub-domains are continuous, which confirms correctness of the performed simulation.

\section{CONCLUSIONS}

This paper presents application of the boundary element method to a 2D steady analysis of complex multi-regions, and proves its utility for simulation of linear thermal bridges. The developed BEM algorithm assumes the Robin condition.

Authoring BEM Fortran program has been successfully validated with two cases: analytical and numerical, according to ISO 10211. In order to classify BEM as a high precision method for modeling thermal bridges, the temperatures and heat fluxes should correspond with reference values listed in the mentioned standard. BEM satisfies this condition for a relatively small number of boundary elements. Obtained BEM solution errors are comparable with FDM errors calculated for a relatively big number of nodes.

Further, a program was applied for determination of the temperature distribution in two complex multi-regions: wallroof junction and wall-balcony board junction, consisting of 9 and 18 sub-regions, respectively.

Performed validation with both examples prove utility of the boundary element method for simulation of temperature and heat flux in complex building structures. Hence, BEM constitutes a great alternative to the mesh methods (FDM, FEM) commonly applied in commercial programs and constitutes the efficient engineering tool for modeling thermal bridges.

\section{Acknowledgments}

The work described in this article was supported by Bialystok University of Technology Research Project S/WBiIŚ/4/14 and funded by Polish Ministry of Science and Higher Education.

\section{References}

[1] J. Mackerle, FEM and BEM in the context of information retrieval, Computers and Structures 80, 1595-1604 (2002).

[2] J.T. Katsikadelis, Boundary Elements. Theory and Applications, Elsevier Science, Oxford 2002.

[3] C.A. Brebbia, J.C.F. Telles, and L.C. Wrobel, Boundary Element Techniques: Theory and Applications in Engineering, Springer-Verlag Berlin, Heidelberg 1984.

[4] M. Ramšak and L. Škerget, 3D multidomain BEM for solving the Laplace equation, Engineering Analysis with Boundary Elements 31, 528-538 (2007).

[5] M. Ramšak and L. Škerget, 3D multidomain BEM for a Poisson equation, Engineering Analysis with Boundary Elements 33, 689-694 (2009).
[6] J. Chatterjee, D.P. Henry, F. Ma, and P.K. Banerjee, An efficient BEM formulation for three-dimensional steady-state heat conduction analysis of composites, International Journal of Heat and Mass Transfer 51, 1439-1452 (2008).

[7] X.-W. Gao and J. Wang, Interface integral BEM for solving multi-medium heat conduction problems, Engineering Analysis with Boundary Elements 33, 539-546 (2009).

[8] X.-W. Gao and T.G. Davies, 3D multi-region BEM with corners and edges, International Journal of Solids and Structures 37, 1549-1560 (2000).

[9] M. Akif Atalay, E. Dilara Aydin, and M. Aydin, Multi-region heat conduction problems by boundary element method, International Journal of Heat and Mass Transfer 47, 1549-1553 (2004).

[10] E. Majchrzak, Boundary element method in heat transfer, Częstochowa University of Technology, Częstochowa 2001, in Polish.

[11] Q. Xu and D-S. Yang, Solving multi-domain 2D heat conduction problems by the least squares collocation method with RBF interpolation on virtual boundary, Engineering Analysis with Boundary Elements 42, 37-44 (2014).

[12] F. Branco, A. Tadeu and N. Simőes, Heat conduction across double brick walls via BEM, Building and Environment 39, 51-58 (2004).

[13] A. Tadeu, J. Prata and N. Simőes, Dynamic simulation of three-dimensional heat conduction through cylindrical inclusions using a BEM model formulated in the frequency domain, Applied Mathematics and Computation 261, 397-407 (2015).

[14] E. Majchrzak, B. Mochnacki and M. Jasiński, Numerical modelling of bioheat transfer in multi layer skin tissue domain subjected to a flash fire, Computational Fluid and Solid Mechanics II, 1766-1770 (2003).

[15] E. Majchrzak, J. Mendakiewicz and A. Piasecka-Belkhayat, Algorithm of mould thermal parameters identification in the system casting mould environment, Journal of Materials Processing Technology 164-165, 1544-1549 (2005).

[16] A. Ben Larbi, Statistical modelling of heat transfer for thermal bridges of buildings, Energy and Buildings 37, 945-951 (2005).

[17] R. Yumrutaş, M. Ünsal, and M. Kanoðlu, Periodic solution of transient heat flow through multilayer walls and flat roofs by complex finite Fourier transform technique, Building and Environment 40, 1117-1125 (2005).

[18] G. Mao and G. Johannesson, Dynamic calculation of thermal bridges, Energy and Buildings 26, 233-240 (1997).

[19] F. Asdrubali, G. Baldinelli, and F. Bianchi, A quantitative methodology to evaluate thermal bridges in buildings, Applied Energy 97, 365-373 (2012).

[20] A. Tadeu, I. Simőes, N. Simőes, and J. Prata, Simulation of dynamic linear thermal bridges using a boundary element method model in the frequency domain, Energy and Buildings 43, 3685-3695 (2011).

[21] EN ISO 10211:2007, Thermal bridges in building construction - Heat flows and surface temperatures - Detailed calculations.

[22] PN-EN 12831:2006, Heating systems in buildings - method for calculation of the design heat load, in Polish.

[23] PN-EN ISO 6946: Building components and building elements - Thermal resistance and thermal transmittance Calculation method, in Polish. 

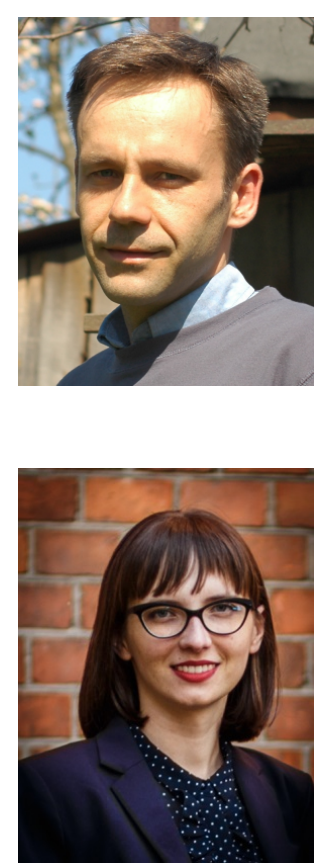

Piotr Rynkowski is a PhD holder at the HVAC Department at Bialystok University of Technology. He received his PhD degree in Environmental Engineering in 2008 from Bialystok University of Technology, Poland, specializing in BEM application for heat conduction problems in complex objects with and without internal heat sources. His field of interest covers application of BEM for solving heat transfer problems, renewable heat sources (especially heat pumps), protection from noise and vibrations.

Anna J. Werner-Juszczuk is a PhD candidate at Bialystok University of Technology, the HVAC Department. Her current research focuses on mathematical modelling of heat transfer in complex building structures and structures with radiant heating systems. She specialises in application of BEM and FEM for solving problems connected with environmental engineering. 